\title{
No hace falta que sonría
}

\section{It is not necessary to smile}

\author{
Rosa Vázquez Recio*
}

Recibido: 16 de diciembre de 2020 Aceptado: 19 de enero de 2021 Publicado: 27 de julio de 2021

To cite this article: Vázquez Recio, R. (2021). No hace falta que sonría. Márgenes, Revista de Educación de la Universidad de Málaga, 2 (2), 130-135

DOI: http://dx.doi.org/10.24310/mgnmar.v2i2.11253

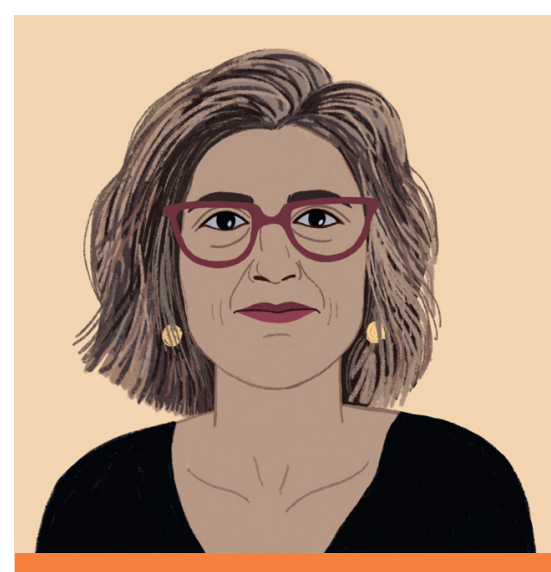

Rosa Vázquez Recio

\section{RESUMEN}

Esta historia mínima se presenta como un modo de provocar la reflexión en torno a una cuestión que viene imponiéndose, de manera callada y acrítica, en la vida cotidiana de la ciudadanía. La felicidad como mercancía y como fin, creando un mundo ilusorio y tan falso como el "sueño americano”. Está sujeta a la oferta y a la demanda y a las exigencias del mercado. Detrás, la gran industria promovida por la psicología positiva, el pensamiento positivo, la economía de la felicidad, el capitalismo emocional. Mientras tanto, y en los márgenes, cuando no en el olvido, siguen existiendo las desigualdades y las injusticias.

Palabras clave: felicidad; mercado; capitalismo emocional; pensamiento positivo; psicología positiva

\section{ABSTRACT}

This minimal story is presented as a way of provoking reflection on an issue that has been imposed, quietly and uncritically, in the daily life of citizens. Happiness as a commodity and as an end, creating an illusory world as false as the "American dream". It is subject to supply and demand and market demands. Behind, the great industry promoted by positive psychology, positive thinking, the economics of happiness, emotional capitalism. Meanwhile, and on the sidelines, when they are not forgotten, inequalities and injustices continue to exist.

Keywords: happiness; market; emotional capitalism, positive thinking, positive psychology

\section{ACTO PRIMERO}

No era un día como cualquier otro. La lengua intentaba expresarse con la misma libertad que lo solía hacer cada mañana tras despertar, pero no conseguía sobrepasar una barrera que no llegaba a descifrar. "Estoy más dormido de lo que pensaba; 
estaré soñando". Pero ese pensamiento no solo fue fugaz sino erróneo. No estaba dormido, estaba despierto, y bien despierto. Aquella sensación de encarcelamiento afectaba a toda la cara, la sentía acolchada, adormecida, con dificultades para gesticular. No quiso preocuparse más de lo necesario, ya tenía suficientes preocupaciones echadas a la espalda. Se levantó despacio, como si el cuerpo no le respondiera. "Otro día más, otro día más”. Con el ánimo por los suelos, más allá de las suelas de las zapatillas, se dirigió al cuarto de baño. Andaba porque tenía que andar, era el automatismo aprendido del cuerpo. "Si te levantas, tienes que andar. No te puedes quedar parado. ¿Parado? Así estoy yo, parado”.

El pasillo enjuto parecía interminable. El cuarto de baño resultaba inalcanzable, pues, a medida que avanzaba, parecía que se desplazaba; casi como si estuviera jugando al pillapilla. Un camino eterno, y solo para llegar al cuarto de baño. Llegó cansado, aún más de lo que estaba cuando se había levantado. El espacio no daba para mucho; los accesorios estaban dispuestos bajo un estricto cálculo: una pequeña placa de ducha con cortina, un wáter, un pequeño lavabo, un espejo, unas tablas con toallas y los utensilios de aseo. Y poco más. Se dispuso delante del lavabo para, de una vez por todas, intentar que esa sensación facial que lo tenía paralizado desapareciera. Ni siquiera hizo el intento de mirarse al espejo; se zambulló en el espléndido chorro de agua helada que salía de un grifo medio oxidado. Se frotó la cara con tanto empeño que pareciese querer sacarle brillo a una piel que había perdido la luz. Era un hombre parado con un rostro apagado.

Había encendido la pequeña radio que mantenía con vida gracias a sus mañas para arreglar esos artilugios; con un poco de esparadrapo conseguía que aquella pequeña caja le acompañara todas las mañanas. Mientras se hallaba entregado a la tarea de la liberación, sonaba aquella voz dulce de la locutora de radio: "Hay que empezar el día con optimismo; no nos podemos dejar vencer por los problemas. ¡Tú puedes, tú puedes! Persigue tu sueño, ¡persigue la felicidad!”. Aquellas palabras desfilaron por sus conductos auditivos, pasando del oído externo al interno, al tiempo que en su cabeza retumbaba “ipuedo ser feliz, yo puedo, yo puedo!”. Cerró el grifo, 


\section{"En su desierto} facial solo quedaban las cicatrices $[. .$.$] .$ Los siete puntos de la infancia se habían conservado; los siete puntos de una etapa feliz." apoyó las manos en el filo arañado del lavabo y levantó la cabeza, dirigiendo la mirada al espejo ovalado que su madre le había regalado, sin querer perder tiempo en coger la toalla y secarse la cara. Se quedó sin palabras, nunca mejor dicho, porque no podía pronunciar palabra alguna. Sus labios habían desaparecido, ni siquiera quedaba rastro de las comisuras, como una evidencia de que ahí, el día anterior, habían existido unos labios. En su desierto facial solo quedaban las cicatrices que recordaban aquella caída del columpio en la que se partió la barbilla siendo un niño. Los siete puntos de la infancia se habían conservado; los siete puntos de una etapa feliz.

Su cuerpo no respondía. Permaneció en la misma posición varios minutos. Sus ojos, clavados en el espejo, intentaban descifrar aquello que estaba viendo. "No tengo labios”. La lengua, ante tal descubrimiento, empezó a moverse en la cavidad, tropezando con la dentadura; así comprobó que solo habían desaparecido los labios. La saliva se le agolpaba y tenía que tragar antes de que la lengua se ahogase en su propio jugo. De nuevo, la voz dulce de la locutora. "La esperanza es lo último que se pierde. ¡No lo olviden! Porque siempre hemos de sonreírle a la vida. ¡Y tú puedes hacerlo!, ¿a qué esperas? Pensamiento positivo, pensamiento positivo, ¡no lo olviden!”.

Aquellas palabras rebotaban en su cabeza como si fueran pelotas de pin-pon, al tiempo que la mirada seguía clavada en el espejo. Tomó aire y se acercó la mano derecha al rostro. " Pensamiento positivo, pensamiento positivo! No pasa nada, tranquilo, solo han desaparecido los labios" - se decía al ritmo de unos dedos que exploraban un territorio con cicatriz como si fuera la primera vez que lo tocara-.

El reconocimiento facial confirmaba lo que minutos antes sus ojos habían descubierto. Allí no había rastro, no quedaba nada, pero "la esperanza es lo último que se pierde. Lo he perdido casi todo, pero tengo que seguir para adelante. Lo ha dicho la locutora”. Por mucho que aquellas palabras quisieran sanar el estado en el que se encontraba, su cuerpo no dejaba de experimentar escalofríos; descargas eléctricas que intentaban contrarrestar aquellas palabras que solo eran propaganda. Y él lo sabía, en el fondo, sabía que era una plétora de consignas que 
solo conducían a una felicidad falsa. Pero quería ser feliz, y se auto-motivaba y se auto-engañaba mientras seguía mirándose en el espejo. "No tengo trabajo, me estoy quedando sin ahorros, no sé cuánto tiempo podré permanecer en este piso, pero lo material no importa para ser feliz, eso dicen, y si lo dicen por la radio será verdad. No creerlo es problema mío, como todos mis problemas”.

Salió del cuarto de baño con un ritmo igual de alicaído que con el que llegó una hora antes. Tomó el pasillo y entró en el salón-cocina. Se dirigió al pequeño mueble del televisor y abrió uno de los cajones, aquel en el que guardaba papeles, algún bolígrafo, rotuladores y todo aquello que no sabía dónde colocar. Rebuscó concienzudamente hasta encontrar lo que quería. Cerró el cajón y de nuevo se dirigió al cuarto de baño, ahora con un pisar más decidido, sin arrastrar los pies. Había llegado la hora. No había marcha atrás. “¡Tú puedes hacerlo, tú puedes!”. Se colocó delante del espejo, se miró sin titubeos. Respiró hondo. La lengua se había calmado y la saliva había vuelto a los niveles normales. Todo estaba bajo control. Se metió la mano en el bolsillo del pantalón de pijama y sacó suavemente el objeto que minutos antes había guardado. Lo tomó con las dos manos y con un suave movimiento consiguió quitar el protector de la punta. Sus ojos ahora estaban clavados en aquello que sus manos portaban y que iba a cambiar el rumbo de su vida. Bajó los párpados de manera decidida, nuevamente respiró, y lo hizo tan hondo que el aire salió para no volver. Dejó el protector junto al grifo, y dirigió su mano derecha al rostro con seguridad y firmeza, calculando bien para no errar. Con delicadeza hizo el movimiento, sin titubeos. Tenía que hacerlo de un tirón para no arrepentirse $\mathrm{y}$, sobre todo, para evitar un desenlace desafortunado. “¡Conseguido!”.

Ahora, su desierto facial lucía una enorme sonrisa roja.

\section{ACTO SEGUNDO}

Esta narración solo pretende ser una invitación a la reflexión, por ello no hace falta que sonría. Esta historia está inspirada en el dibujo de Mana Neyestani1: una po-

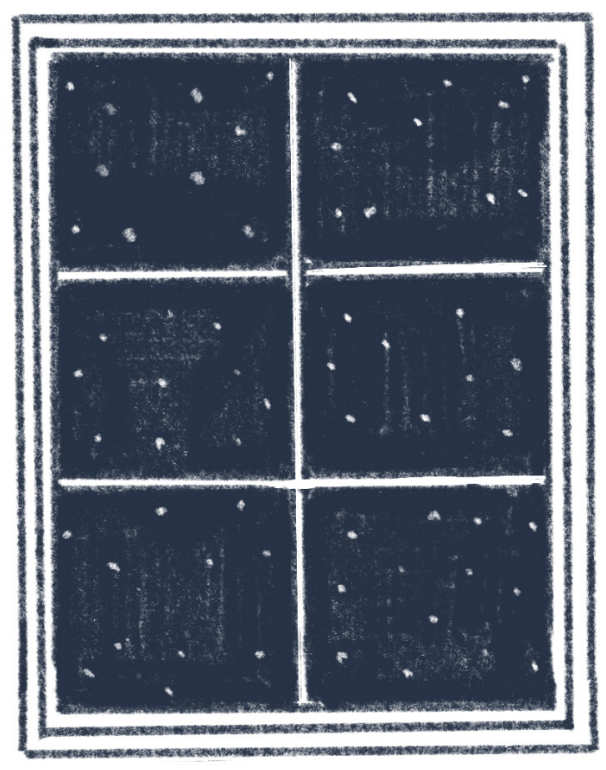

1 Imagen disponible aquí: https://www.rferl.org/a/mana_neyestani_ works_cartoons/24543707.html 
"Se produce así una despolitización que termina encubriendo la violencia estructural que ejerce el sistema sobre la ciudadanía[...]." rra sobre la boca de un hombre con un rostro sufrido, angustiado; en la porra hay dibujada una sonrisa, que contrasta con la historia que cuenta ese rostro: "sonría”. Pero también deviene de la reflexión sobre el fenómeno que se viene produciendo en los últimos tiempos y que tiene que ver con el movimiento de la psicología positiva, el pensamiento positivo y la economía de la felicidad. Detrás de esta maquinaria hay un propósito y un interés nada nuevo: la manipulación del ser humano en clave de productividad y consumo; de hacer a este responsable de sus problemas y circunstancias (ser rico o pobre, tener éxito o fracasar, ser feliz o no...). Problemas y circunstancias individuales que requieren de respuestas y soluciones individuales. El bien de la sociedad se alcanza como efecto del bien individual. Es la mercantilización y la despolitización de los asuntos colectivos, los cuales remiten al bien común.

La sonrisa de la narración, como la del dibujo, es impostada. La pintura de una sonrisa no rivaliza con la que puede ser una sonrisa sentida, con credibilidad; esto, en sí mismo, no implica un problema. Sin embargo, adquiere relevancia y valor cuando el simulacro simboliza lo que puede resultar un efecto del capitalismo emocional que toma la felicidad — la sonrisa es un signo de esta- como una mercancía, un producto del mercado que moviliza toda una industria. En tal caso, la dialéctica aflora porque nos sitúa en un plano ético y político, que es, precisamente, lo que se anula para hacer de la felicidad un asunto puramente técnico que puede ser medido, controlado, manipulado. Se produce así una despolitización que termina encubriendo la violencia estructural que ejerce el sistema sobre la ciudadanía, con una repercusión desigual que contribuye a mantener las desigualdades sociales (como el resto de desigualdades posibles: educativas, cognitivas, económicas, afectivas...). Simular una sonrisa es una muestra de la alienación a las exigencias de un orden social marcado por una economía de mercado que instiga al sujeto de consumo a consumirfelicidad; una felicidad que no solo es efímera, sino que es, igualmente, simulada. El sufrimiento, ligado a la infelicidad, no puede ser eli- 


\section{H I S T O R I A S M Í N I M A S}

minado ni negado, más cuando las condiciones que lo generan no parecen que estén en la agenda de las políticas neoliberales y del capitalismo financiero.

La sonrisa podrá ser impostada, pero las desigualdades y las injusticias difícilmente podrán responder a la cultura del simulacro (Baudrillard, 1995), ni les será efectivo el "factor de esperanza" al que se agarran quienes son defensores de la industria de la felicidad (Cabanas y Illouz, 2020). Aunque sean escondidas bajo una "pintura roja”, seguirán siendo sufridas, y tal vez por ello sea preciso hacer algún "elogio a la infelicidad" (Lledó, 2005) que humanice la sonrisa.

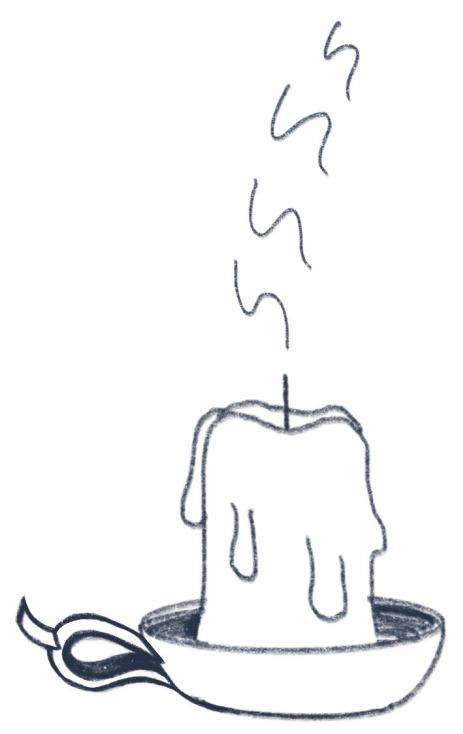

\section{REFERENCIAS}

Baudrillard, J. (1995). Cultura y simulacro. Kairós.

Cabanas, E. y Illouz, E. (2020). Happycracia. Cómo la ciencia y la industria de la felicidad controlan nuestras vidas. Paidós.

Lledó, E. (2005). Elogio a la infelicidad. Cuatro Ediciones. 